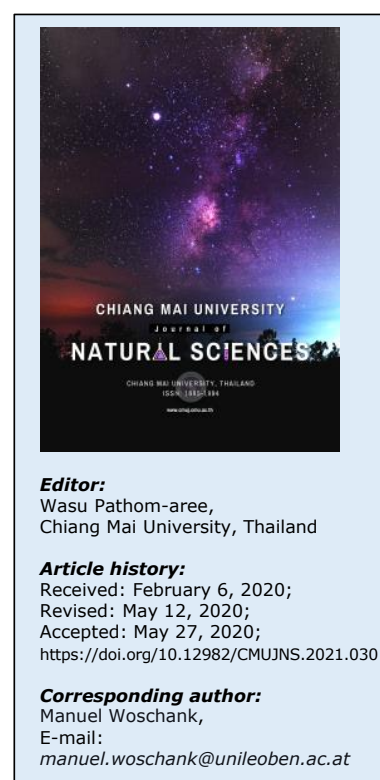

Research article

\section{Smart Logistics - Conceptualization and Empirical Evidence}

Manuel Woschank* and Helmut Zsifkovits

Montanuniversitaet Leoben, Leoben, Austria

Abstract Industry 4.0 approaches have gained increasing relevance and impact on logistics research and practical applications. However, logistics research often focuses on the investigation of isolated concepts, which leads to a systematic neglect of more holistic research frameworks. Therefore, this paper conceptualises Smart Logistics as an important element within the context of Industry 4.0 approaches. Furthermore, a set of technological concepts for Smart Logistics is identified and potential applications are outlined and discussed. Moreover, the paper presents recent developments in the area of Smart Logistics based on both primary and secondary data analyses and recommends further directions for future research efforts.

Keywords: Industrie 4.0, Industry 4.0, SME 4.0, Smart Logistics, Smart Supply Chain Management

Funding: The project "SME 4.0 - Industry 4.0 for SMEs" has received funding from the European Union's Horizon 2020 research and innovation program under the Marie Skłodowska-Curie grant agreement No. 734713.

Citation: Woschank, M. and Zsifkovits, H. 2021. Smart logistics - conceptualization and empirical evidence. CMUJ. Nat. Sci. 20(2): e2021030 


\section{INTRODUCTION}

Digitalisation can be seen as a central topic for the development of the global economy and modern society. Successful digitalisation strategies are identified as important drivers of continuous growth and long-term welfare. Therefore, digitalisation strategies within enterprises are frequently supported by governmental initiatives that aim at improved innovation power, higher productivity, lower costs, higher revenues, better training of employees in terms of digitalisation readiness and enhanced competitive advantages (FFG, 2019).

In general, the term "Industry 4.0 " comprises a multitude of digitalisation strategies, approaches and technologies by mainly focusing on the application in the industrial environment. Thereby, the areas of application range from product development, construction and manufacturing to the improvement of material flows. These initiatives should help industrial enterprises to meet objectives such as increased competitiveness based on transparent processes, higher agility, enhanced adaptability and improved flexibility (Statista, 2015).

The basic principles of the Industry 4.0 approaches can be classified as 1 ) digital interconnectivity approaches and 2 ) self-controlling systems approaches (Bosch et al., 2017). Interconnected production networks simultaneously collect real-time information regarding every component being produced, their storage locations and transition points by using sensors, actors and further intelligent identification tracking systems. Products, components and raw materials automatically contain all necessary information regarding their condition, quality and real-time status. Every node and edge of the production network is interconnected and, furthermore, is able to communicate with other nodes. Partial or complete self-control is ensured by a set of process rules and/or algorithms. Production steps, production sequences and production lot sizes can be dynamically adapted to the new requirements. Inventory levels are monitored in real-time leading to automatic ordering processes and enhanced control strategies, e.g., dynamic safety stocks (Gudehus, 2012) or supply-chain-wide inventory management approaches (Tempelmeier, 2018). In addition, the digital interconnectivity, selfcontrolling systems, for example, autonomous material flow processes and automatic monitoring and control systems, will play an important role in modern production enterprises. Thereby, the intelligent monitoring and control of supply chain processes can be regarded as an essential prerequisite for the usage of modern technologies (ten Hompel, 2014).

This paper focuses on the digitalisation strategies in supply chains by using a set of technological concepts for the improvement of company-internal and companyexternal material flow processes based on the conceptual framework of Zsifkovits and Woschank (2019). Thereby, in this paper, the authors define Smart Logistics as a major component within the Industry 4.0 approaches, identify a set of technological concepts, discuss potential practical applications and present recent developments in the area of Smart Logistics as well as potential directions for future research.

\section{MATERIALS AND METHODS}

\section{Theoretical framework}

In this subsection, the authors develop the theoretical framework. Therefore, the authors outline and discuss state of the art conceptualisations and combine their insights to a generic Smart Logistics Framework.

In this context, Kagermann et al. (2013) define Industry 4.0 as the technologicalbased integration of Cyber-Physical Systems (CPS) into production and logistics and the application of the Internet of Things (IoT) and services in industrial processes, including all resulting consequences for the value chain, business models, services and labour organisation. Production and logistics are considered as core areas of Industry 4.0 while business models and other corporate functions will only play a minor role. Following 
these classifications, the authors define Smart Logistics as a core element of the Industry 4.0 approaches.

Based on a quantitative content analysis of relevant publications, Hermann et al. (2016) have derived four basic formal principles for the implementation of Industry 4.0 approaches which can be operationalised as 1) the assurance of digital interconnectivity, 2) the decentralisation of decision-making processes, 3) the availability of transparent information and 4) the usage of technical assistance systems.

Moreover, Bechtold et al. (2014) have created a framework which consists of the eight important value drivers based on the four pillars of Industry 4.0, namely, 1) Smart Solutions, 2) Smart Innovations, 3) Smart Supply Chains and 4) Smart Factory. In contrast to Kagermann et al. (2013), in this model, products and services respectively innovation processes are conceptualised as independent elements. This framework should be used to ensure continuous growth and enhanced efficiency based on an organisational framework that includes an agile operating model, human resource management, change management, corporate governance, processes and digital infrastructure.

Based on the previously outlined models and in combination with the elaboration of Rauch et al. (2018), the authors propose a new framework of Smart Logistics which is displayed in Figure 1 (Kagermann et al., 2013; Bechtold et al., 2014; Rauch et al., 2018; Zsifkovits and Woschank, 2019). Thereby, Smart Logistics includes intelligent and smart supply chains, based on agile cooperation in interlinked networks and the digital interconnectivity of organisations. The digital interconnectivity is assured by state-of-the-art information and communication technologies (ICT), data networks, sensors and actors and intelligent technologies for identification and tracking of materials, components and/or products, respectively. Autonomous transport vehicles in combination with automated warehouses as well as storage and handling infrastructure enable complete or at least partial self-control of internal and external material flow processes.

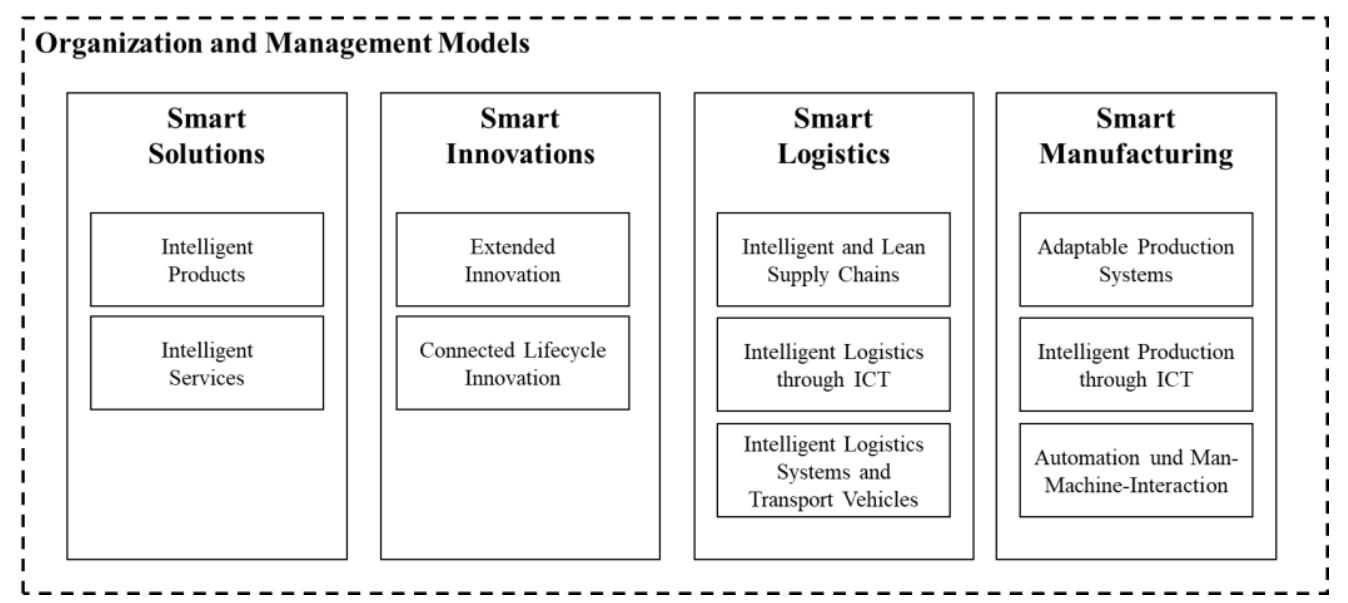

Figure 1. Smart Logistics Framework.

\section{Conceptual framework of technologies for Smart Logistics}

In this section, the authors outline a set of technological concepts for Smart Logistics and discuss potential applications. Therefore, recent literature has developed a multitude of divergent frameworks, models and conceptualisations. For example, Bechtold et al. (2014) identify the following main technological concepts as the main enablers of Industry 4.0: 1) cloud computing, 2) mobile technologies, 3) robotics, 4) advanced analytics, 5) machine-to-machine-communication, 6) social media and 7) 3D printing. This classification can be regarded as unspecific because of a missing unambiguous classification of technologies as enablers for Smart Production and/or Smart Logistics initiatives. Subsequently, the authors describe the concepts of the Cyber-Physical Systems (CPS) CPS, the Internet of Things (IoT) and the Physical 
Internet (PI) as the core elements of the proposed Smart Logistics component within the Smart Logistics Framework.

Cyber-Physical Systems (CPS). CPS are physical objects or structures, such as products, devices, buildings, means of transport, production facilities and logistics components, that include embedded systems to ensure interactive communication (Bauernhansl et al., 2014). The systems are connected through local and global digital networks (Broy, 2010) by using sensors and actors in closed control loops (Lee, 2010). CPS detect, analyse and capture their surrounding environment by using sensors combined with available information and services. Moreover, actors are used to interact with physical objects. CPS act autonomously, decentrally, can build up a network amongst themselves and can independently optimise themselves according to the principles of self-similar fractal production systems. The Smart Factory interacts with human resources and/or machines and is able to organise itself in a decentralised, realtime-based way (Bauernhansl et al., 2014).

A virtual image of the reality is permanently analysed and updated with real-time information. Therefore, the virtual environment, often called the "Digital Twin", is always synchronised with information from the real environment. This can be seen as the starting point to connect the Internet of Mankind to the IoT and to the Internet of Services (Padovano et al., 2018).

Internet of Things (IoT). The IoT can be seen as an essential and important part of the CPS and which is often associated with Radio Frequency Identification (RFID) technologies. Thereby, the IoT is used to identify and track objects (e.g., products, containers, machines, vehicles) in logistics systems and supply chains. The objects are constantly processing information about their surrounding environment and can be unambiguously allocated, which increases the effectiveness and efficiency of all related monitoring and control processes (Borgmeier et al., 2017; Boyes et al., 2018).

Physical Internet (PI). The PI is an open, standardised, worldwide freight transport system based on physical, digital and operative interconnectivity by using protocols, interfaces and modularisation. A provider-free, industry-neutral and borderfree standardisation is one of the basic requirements for usage of the PI, which connects and virtualises material flows, analogous to the concept of the digital internet. Moreover, standardised containers and carriers are used to ensure a maximum utilisation of transport vehicles and a better usage of spare capacities. These principles can be applied in internal logistics systems, as well as in transportation networks by using self-controlling, autonomous systems in transport and storage processes as one of the central elements of the PI. The usage of shared transport capacities, storage locations, hubs and delivery points will have a positive effect on both economic (e.g., short transportation times, lower costs of human resources) and ecological (e.g., reduction of traffic and emissions) effects (Montreuil, 2011; Pan et al., 2017).

As a finding from the theoretical and conceptual analyses, Smart Logistics will be able to contribute to an enhanced efficiency of supply chains and to sustainable growth of industrial enterprises based on new business models by taking advantage of the following potentials:

- Enhanced control of processes based on real-time information

- Dynamic and situationally orientated design of processes in the sense of adaptive and self-controlling systems

- Utilisation of synergies by sharing capacities on neutral and independent platforms

- Increased decision-making processes based on extensive data analyses (Data Analytics) in combination with closed-loop learning systems

- Ability of a flexible and customised adaptation of products, services and processes

- Individualisation of designs, configuration options, orders, planning procedures, production processes and ongoing operation under economic conditions

- Effective man and machine interaction by including new principles of work design and competence utilisation 
- Realising new potentials for logistics management through the development of new business models and innovative services.

\section{RESULTS}

\section{Preliminary empirical evidence}

In this subsection, the authors evaluate preliminary evidence for the proposed Smart Logistics Framework based on research-subjected-related literature in logistics management research. For this purpose, the authors focus on relevant studies published over the timeframe from 2008 to 2018 . According to the previously deducted framework, the evaluation will be divided into the sections of: 1) Smart Solutions, 2) Smart Innovations, 3) Smart Logistics and 4) Smart Manufacturing.

Smart Solutions. Smart Solutions are realised by the implementation of Smart Products and Smart Services. Smart Products which are based on Product Enabled Information Devices (PEID), such as RFID, sensors and actors, allow the interoperability of systems by dynamically exchanging product data and additional in-depth information regarding the lifecycle management (Kiritsis, 2011), product-based information and manufacturing-process-related information (Filho et al., 2017).

This may also result in increased new product and process innovations. For example, the equipping of clothes with sensors can lead to better information for the development of new materials (Gomes et al., 2018), a better usage of production and logistics systems through permanent condition monitoring and an ongoing optimisation of operation settings (Schuetze et al., 2018). Moreover, Industry 4.0 approaches can be used the create Smart Services, e.g., cloud manufacturing based on the interconnection of manufacturing enterprises through virtual network technologies, which enables the usage of distributed manufacturing resources ( $\mathrm{Li}$ and Yao, 2018), collaborative development activities (Enrique et al., 2018) and collaborative transportation strategies (Behrends et al., 2016).

Smart Innovations. Smart Innovations can be realised by developing cooperative innovation strategies and open innovation models which could also be useful for small- and medium-sized enterprises (SME) to transform company-internal innovation processes into a dynamic process within company networks (Silviana, 2018).

Smart Logistics. In the area of Smart Logistics, the usage of sensors, actors and CPS increases the accuracy and real-time availability of information and lowers the costs of the supply-chain-wide tracking and tracing systems (Louw and Walker, 2018). Moreover, a consistent monitoring of products without human participation is possible. For example, this can help food companies, to improve their logistics processes, competitiveness and reinforce the confidence of consumers in the quality of the food supply chain (Abad et al., 2009). Logistics systems can increase their efficiency by internally implementing real-time planning and control systems (Qu et al., 2012) and externally synchronising information by using cloud-based approaches (Qu et al., 2016) or deep reinforcement learning algorithms (Waschneck et al., 2018). Moreover, automated guides vehicles (AGV) become more and more important for industrial enterprises. Thereby, Mehami et al. (2018) have identified the ability of reconfiguration, the flexibility and the customisability, as the main success factors of an effective AGV implementation. In addition, warehousing processes are optimised by the usage autonomous robots, intelligent carriers and advanced assistance systems for man-machine-interaction (Glock and Grosse, 2017).

Smart Manufacturing. Smart Manufacturing uses advanced data analytics to gain valuable insights about the manufacturing processes to increase production efficiency, planning accuracy and achieve reduction in costs. However, the implementation requires a significant initial investment (Mehta et al., 2018). In this context, decision support systems can be used to allow a systematic evaluation among 
different scenarios to take better decisions (Grieco et al., 2017). Moreover, Industry 4.0 strategies can be seen as enablers of automation by reducing the time from failure occurrence to failure notification by automatically triggering fault-repair actions through Smart Devices. The continuous flow of materials can be supported by digital assisting systems based on augmented reality, employees get individualised information about necessary tasks to get along in timed productions and decentralised working stations could negotiate cycle times and, thus, find the optimum between highest possible capacity utilisation per working station and a continuous flow of goods (Kolberg and Zuehlke, 2015). CPS can also be used to identify weak spots in the production process by predicting product quality based on process data analytics (Lee et al., 2018).

\section{DISCUSSIONS AND CONCLUSIONS}

In general, based on the Industry 4.0 approaches, Smart Logistics can be identified as a crucial element of digitalisation in the industrial value chain. Smart Logistics is based on the usage of agile cooperation networks and on the information in respect to organisation-based connectivity to enable intelligent and lean supply chains (Kagermann et al., 2013; Bechtold et al., 2014; Rauch et al., 2018; Zsifkovits and Woschank, 2019).

CPS, the IoT and the PI can be seen as integral concepts of Smart Logistics, aiming at an increased supply chain efficiency by the creation of (partly) autonomous systems and processes. Independent platforms for logistics services (e.g., transportation, storage, packaging, control of material and information flow) contribute to a better usage of resources and to the creation of new business models. Advanced data analytics provide tools for more efficient decision-making processes Bauernhansl et al., 2014; Borgmeier et al., 2017; Montreuil, 2011).

The consistent traceability of material flows based on new methods of automated identification and tracking, the development of self-controlled autonomous systems for transport and storage and the increased usage of advanced data analytics can be regarded as the first steps on the path to Smart Logistics (Zsifkovits et al., 2020).

In this context, the following future challenges are identified: The establishment of the provider-free, industry-neutral and border-free standardisation of systems and interfaces in material- and information-flow processes; the definition of business cases to evaluate the benefits of investments in new technologies; the development of innovative organisational models for the integration of new technologies; the assurance of the security for human resources and data (Cyber Security); the further development and promotion of digitalisation competences in vocational education and training incentives; and the continuing integration of emerging technologies (e.g., artificial intelligence (AI), machine learning, etc.) into logistics processes (Dallasega et al., 2020).

Moreover, future research should further investigate the proposed Smart Logistics Framework by focusing on synergies and/or interconnectedness, potential effects and risks, respectively barriers in the implementation phase of the developed subcategories.

\section{ACKNOWLEDGEMENTS}

This article is an updated and completely revised version of the conceptual paper by Zsifkovits and Woschank (2019). 


\section{REFERENCES}

Bauernhansl, T., Ten Hompel, M., and Vogel-Heuser, B. 2014 (eds). Industrie 4.0 in produktion, automatisierung und logistik: anwendung, technologien, migration. Springer, Wiesbaden.

Bechtold, J., Lauenstein, C., Kern, A., and Bernhofer, L. 2014. Industrie 4.0 - eine einschätzung von capgemini consulting: der blick über den hype hinaus. capgemini consulting; [Cite 2019 Jan 15] Available from. https://www. capgemini.com/de-de/wp-content/uploads/sites/5/2017/07/industrie-4.0-de.pdf.

Behrends, V., Haunschild, M., and Galonske, N. 2016. Smart Telematics Enabling Efficient Rail Transport - Development of the ViWaS Research and Development Project. Transportation Research Procedia. 14: 4430-4439.

Borgmeier. A, Grohmann, A., and Gross, S.F. (eds). 2017. Smart Services und Internet der Dinge: Geschäftsmodelle, Umsetzung und Best Practices: Industrie 4.0, Internet of Things (IoT), Machine-to-Machine, Big Data, Augmented Reality Technologie. Hanser, München.

Bosch, G., Bromberg, T., Haipeter, T., and Schmitz, J. 2017. Industrie und arbeit 4.0: befunde zu digitalisierung und mitbestimmung im industriesektor auf grundlage des projekts "arbeit 2020". IAQ-report: aktuelle forschungsergebnisse aus dem institut arbeit und qualification; [Cited 2017 Apr]. Available from https://duepublico.uni-duisburg-essen.de/servlets/DerivateServlet/Derivate45107 /Bosch_et_al_Industrie_und_Arbeit_4_0.pdf.

Boyes, H., Hallaq, B., Cunningham, J., and Watson, T. 2018. The industrial internet of things (IIOT): An analysis framework. Computers in Industry. 101: 1-12.

Broy, M. 2010 (ed). Cyber-physical systems: innovation durch software-intensive eingebettete systeme. Springer, Berlin.

Dallasega P., Woschank M., Zsifkovits H., Tippayawong K., and Brown, C.A. 2020. Requirement analysis for the design of smart logistics in SMEs. Matt DT, Modrák $\mathrm{V}$, Zsifkovits $\mathrm{H}$, (eds). Industry 4.0 for SMEs. Cham: Springer. p. 147-162.

Enrique, D.V., Ayala, N.F., Lima, M.J.d.R.F., Marodin, G.A., Gzara, L., and Frank, A.G. 2018. The use of ICT tools to support collaborative product development activities: evidences from Brazilian industry. Production. 28: 323.

FFG (Federal Ministry Republic of Austria. Digital Economic Affairs). 2019. Digitalisation Agency. FFG; [Cited 2019 Jan 15]. Available from https://www.ffg.at/en/ node/70661.

Filho, M.F., Liao, Y., Loures, E.R., and Canciglieri, O. 2017. Self-Aware Smart Products: Systematic Literature Review, Conceptual Design and Prototype Implementation. Procedia Manufacturing. 11: 1471-1480.

Glock, C., Grosse, E. (eds). 2017. Warehousing 4.0: Technische Lösungen und Managementkonzepte für die Lagerlogistik der Zukunft. B+G Wissenschaftsverlag, Lauda-Königshofen.

Gomes, P., Tama, D., Yao, Y., Abreu, M.J., Souto, A.P., and Carvalho, H. 2018. Development of pressure sensors for smart textiles. IOP Conference Series: Material Science and Engineering. 460: 12024.

Grieco, A., Caricato, P., Gianfreda, D., Pesce, M., Rigon, V., Tregnaghi, L., and Voglino, A. 2017. An industry 4.0 case study in fashion manufacturing. Procedia Manufacturing. 11: 871-877.

Gudehus, T. 2012. Dynamische disposition: strategien, algorithmen und werkzeuge zur optimalen auftrags-, bestands- und fertigungsdisposition. Springer, Berlin.

Hermann, M., Pentek, T., and Otto, B. 2016. Design principles for industrie 4.0 scenarios. In: Bui, T.X., Sprague, R.H., (eds). Proceedings of the 49th Annual Hawaii International Conference on System Sciences; 2016 jan 5-8. p. 39283937.

Kagermann, H., Helbig, J., Hellinger, A., and Wahlster, W. 2013: Deutschlands zukunft als produktionsstandort sichern: umsetzungsempfehlungen für das zukunftsprojekt industrie 4.0. Abschlussbericht des Arbeitskreises Industrie 4.0. acatech - Deutsche Akademie der Technikwissenschaften e.V.; [Cited 2019 Jan 15]. Available from https://www.bmbf.de/files/Umsetzungsempfehlungen_ Industrie4_0.pdf 
Kiritsis, D. 2011. Closed-loop PLM for intelligent products in the era of the internet of things. Computer-Aided Design. 43: 479-501.

Kolberg, D., Zuehlke, D. 2015. Lean Automation enabled by Industry 4.0 Technologies. IFAC-PapersOnLine. 48: 1870-1875.

Lee, E.A. 2010. CPS foundations. In: Sapatnekar, S. (ed). Proceedings of the $47^{\text {th }}$ Design Automation Conference. The $47^{\text {th }}$ Design Automation Conference; Anaheim, California. New York, NY: ACM. p. 737.

Lee, J., Noh, S.D., Kim, H.J., and Kang, Y.S. 2018. Implementation of Cyber-Physical Production Systems for Quality Prediction and Operation Control in Metal Casting. Sensors. 18

$\mathrm{Li}, \mathrm{Y}$. , and Yao, X. 2018. Cloud manufacturing service composition and formal verification based on extended process calculus. Advances in Mechanical Engineering. 10: 168781401878128.

Louw, L., and Walker, M. 2018. Design and implementation of a low cost RFID track and trace system in a learning factory. Procedia Manufacturing. 23: 255-260.

Mehami, J., Nawi, M., and Zhong, R.Y. 2018. Smart automated guided vehicles for manufacturing in the context of Industry 4.0. Procedia Manufacturing. 26: 10771086.

Mehta, P., Butkewitsch-Choze, S., and Seaman, C. 2018. Smart manufacturing analytics application for semi-continuous manufacturing process - a use case. Procedia Manufacturing. 26: 1041-1052.

Montreuil, B. 2011. Toward a Physical Internet: meeting the global logistics sustainability grand challenge. Logistics Research. 3: 71-87.

Padovano, A., Longo, F., Nicoletti, L., and Mirabelli, G. 2018. A digital twin based service oriented application for a 4.0 knowledge navigation in the smart factory. IFACPapersOnLine. 51: 631-636.

Pan, S., Ballot, E., Huang, G.Q., and Montreuil, B. 2017. Physical Internet and interconnected logistics services: research and applications. International Journal of Production Research. 55: 2603-2609.

Qu, T., Lei, S.P., Wang, Z.Z., Nie, D.X., Chen, X., and Huang, G.Q. 2016. IoT-based real-time production logistics synchronization system under smart cloud manufacturing. The International Journal of Advanced Manufacturing Technology. 84: 147-164.

Qu, T., Yang, H.D., Huang, G.Q., Zhang, Y.F, Luo, H., and Qin, W. 2012. A case of implementing RFID-based real-time shop-floor material management for household electrical appliance manufacturers. Journal of Intelligent Manufacturing. 23: 2343-2356.

Rauch, E., Matt, D.T., Brown, C.A., Towner, W., Vicerky, A., and Santiteerakul, S. 2018. Transfer of industry 4.0 to small and medium sized enterprises. Advances in Transdisciplinary Engineering. Transdisciplinary Engineering Methods for Social Innovation of Industry 4.0: 7(63-71).

Schuetze, A., Helwig, N., and Schneider, T. 2018. Sensors 4.0 - smart sensors and measurement technology enable Industry 4.0. Journal of Sensors and Sensor Systems 7: 359-371.

Silviana, B.G. 2018. Open innovation model: enabling the market uptake of innovation. Procedia Manufacturing. 22: 893-899.

Statista - Das Statistik-Portal. 2015. Welche Anwendungsbereiche von Industrie 4.0 sind heute bzw. werden zukünftig in Unternehmen stark ausgeprägt sein?. Statista;[Cited 2019 Jan 15]. Available from https://de.statista.com/statistik/ daten/studie/605446/umfrage/anwedungsbereiche-von-indsutrie-40-heute-und -zukuenfitg-in-der-dach-region/.

Tempelmeier, H. 2018. Bestandsmanagement in supply chains. Books on Demand, Norderstedt.

ten Hompel, M. 2014. Logistik 4.0. In: Bauernhansl, T., ten Hompel, M., Vogel-Heuser, B., (eds). Industrie 4.0 in produktion, automatisierung und logistik: anwendung, technologien, migration. Springer, Wiesbaden. p. 615-624.

Waschneck, B., Reichstaller, A., Belzner, L., Altenmüller, T., Bauernhansl, T., Knapp, A., and Kyek, A. 2018. Optimization of global production scheduling with deep reinforcement learning. Procedia CIRP. 72: 1264-1269. 
Zsifkovits, H., and Woschank, M. 2019. Smart logistics - technologiekonzepte und potentiale. Berg- und Huettenmaennische Monatshefte. 615.

Zsifkovits, H., Kapeller, J., Reiter, H., Weichbold, C., Woschank, M. 2020. Consistent identification and traceability of objects as an enabler for automation in the steel processing industry. Matt DT, Modrák V, Zsifkovits $H$, (eds). Industry 4.0 for SMEs. Cham: Springer. p. 163-192.

OPEN access freely available online

Chiang Mai University Journal of Natural Sciences [ISSN 16851994]

Chiang Mai University, Thailand

https://cmuj.cmu.ac.th 